Research, part of a Special Feature on Mental Models

\title{
ARDI: A Co-construction Method for Participatory Modeling in Natural Resources Management
}

\author{
$\underline{\text { Michel Etienne }}^{1}, \underline{\text { Derick R. Du Toit }}^{2}$, and Sharon Pollard ${ }^{2}$
}

\begin{abstract}
The outcomes of a series of tests of the ARDI (Actors, Resources, Dynamics, and Interactions) method in complex cases or conflict-ridden situations is presented. ARDI is part of a companion modeling approach that makes it possible to engage a broad spectrum of stakeholders in the design and development of land and water management plans. It is based on participatory workshops that set out to collaboratively imagine a future open, dynamic management system, capable of adaptation and anticipation, by gathering the various stakeholders in a partnership to examine conservation of the natural resources and promoting a sustainable development. Its originality lies in the co-construction of a "conceptual model" of the functioning of the territory, according to an overarching, negotiated development question. The approach is based on the collective articulation of the key elements of a context or territory by stakeholders such as managers, representatives, socio-professional technicians, nongovernmental organizations, experts, and scientists, and local policy makers. This sharing of representations is done by means of a series of collective workshops during which Actors, Resources, Dynamics, and Interactions constituting the profile of the territory are identified and clarified. This work of co-construction is conducted within a precise methodological framework that we present in a step-by-step format. The method is grounded in concrete experience gleened from tests conducted by the authors over the past five years. Finally, the requirement for specific skills as well as pitfalls to avoid when applying the method are discussed.
\end{abstract}

Key Words: co-construction; collective mental model; conceptual model; facilitation; natural resources management; participatory modeling

\section{INTRODUCTION}

The application of simulation models in collaborative decision making for the management of natural resources is a characteristic of adaptive management (Holling 1978, Walters 1986). But the use of these models to stimulate the participation of stakeholders in the development of management scenarios is much rarer (Costanza and Ruth 1998, Bousquet et al. 2002, Ozesmi and Ozesmi 2004, Bosch et al. 2007). The progressive shift from management planning based on an authoritative or rationalist approach towards the incorporation of tools for mediation based on democratic approaches (Van den Belt 2004) calls for the emergence of new tools that focus on co-construction of meaning and the sharing of information and understanding regarding a particular context that is to be managed.
Environmental issues are often technically complex and deeply embedded in the minds, hearts, and practices of society. As such, their resolution requires the collaboration of public authorities, private business, scientific experts, groups of users, social interest groups, non-governmental organizations, and representatives of stakeholders in the particular ecological domain (Bouwen and Taillieu 2004). Methods and approaches that facilitate the development of shared problem perspectives have improved their effectiveness by melding different kinds of knowledge and different competencies. They do this by involving multiple actors or stakeholders in collectively constructing a social learning process. These processes result in shared or collective mental models of the issues or problem. Recent papers demonstrate that these participatory processes produce better outcomes than classical top-down processes (Lynam et al. 2007, Reed 2008, 
Voinov and Brown 2008, Voinov and Bousquet 2010), particularly in terms of experiential learning about the issue, about solutions to technical problems, about other stakeholders, or about communicational and organizational learning (Daré et al.2010). The role of these participatory processes in social change has barely been evaluated, but recent work on companion modeling (Etienne 2010) provides evidence of interesting changes in social representation of environmental issues (Mathevet et al. 2011) or in social organization to face environmental problems (Gurung et al. 2006).

Following a series of tests of methods conducted in multiple use and multi-stakeholder contexts (natural areas with multiple use, biosphere reserves, regional or national parks) or in conflict situations (heritage sites, urban-forest interfaces), a companion modeling approach was developed and applied, which made it possible to involve stakeholders in the design of land and water management plans (Etienne 2006). This approach is based on participatory workshops that were set up to envision an open, dynamic management approach, capable of adaptation and anticipation, by gathering the various stakeholders together to promote sustainable development and conserve shared resources. Its originality lies in the co-construction of a shared "conceptual model" of the relationships and functioning of the different aspects of a particular context or territory. This is usually conducted in relation to a specific and negotiated development question.

The approach focuses on encouraging participants to describe, explain, and predict the purpose, form, function, and state of a given system (Rouse and Morris 1986), so as to elicit causal knowledge as defined by Jones et al. (2011). It is based on the collective articulation of the key elements of a territory and context by affected stakeholders such as managers, representatives, socio-professional technicians, non-governmental organizations, experts and scientists, and local policy makers. It frames the elicitation of individual learning that then leads to the emergence of collective learning (Röling 2002). This sharing of representations results in the progressive emergence of a collective "mental model" due to changes in the individual's schemas that occur primarily through nonconscious processes in response to experiential learning during repeated exposure to novel ideas and relationships (Beratan 2007). This dialogical process is achieved through a series of collective workshops during which Actors, Resources, Dynamics, and Interactions (ARDI) are identified and clarified by the participants themselves. The work of coconstruction is conducted within a precise methodological framework which we present and illustrate by means of concrete examples from the tests we conducted over the past five years.

\section{KEY QUESTION AND KEY PARTNERS}

The success of participatory modeling depends on three key choices that are made at the start of the process. These choices have to be discussed among the mandatory partners and the facilitators of the approach during one or more preparatory meetings. The first choice involves clearly defining the territory under question and identifying and formulating the question to be addressed. Environmental decision making may encompass conflicts over resource management or hidden sociological or ecological agendas and interests. Thus, formulating a precise and clear question that is easily understood by a wide set of stakeholders is a crucial entry into the ARDI process. When the demand for such an intervention arises directly from local stakeholders, the facilitator should engage with it, identify key stakeholders and participants, and collaboratively define the central question or issue to be addressed. If the demand comes from a scientific interrogation or research, the facilitator has to formulate the central question or objective in a way that will convince key stakeholders to collaborate (Daré et al. 2009).

The second key choice involves identifying one or several facilitator(s). Their aptitude and legitimacy to lead the process of design-validation-use of ARDI tools has to be ascertained.

Thirdly, it is necessary to pay special attention to the composition of the working group: the choice of partners and meeting place, the periodicity of the workshops, and the method of invitation are all important contributors to the success of the method. This is mainly because the representativeness of the participants and thus the richness and relevance of the conceptual model depend on the composition of the group.

The ARDI method has been tested under a variety of conditions, key questions, and contexts. A diversity of territories were involved, including a mountain pasture where contradictory resource 
access rights led to a conflictive situation; a water catchment where compliance with the water law was questioned; a set of municipalities that were concerned with the same forest fire risk; and a wide river delta where many human activities were overlapping. The conditions that led to the use of a participatory modeling process included solving or avoiding potential land use conflicts (Rouan et al. 2010), imagining a more sustainable management scheme for a region (Simon and Etienne 2010, Souchere et al. 2010)), and assessing the impact of a regulation on water (Biggs et al. 2008) or biodiversity management (Anselme et al. 2010).

The success of this approach to natural resources management lies in the relative independence of an external scientific agent who is familiar with and is skilled in handling the methodological aspects. However, there is a distinct advantage to engaging a researcher as facilitator who is skilled in both the ecological sciences and social sciences and who has basic experience in facilitating debates between researchers and managers. But a communication expert can also easily play this role. That is the reason why the method was applied mainly by French researchers who were working in the field of companion modeling (Collectif Commod 2006), but several agents of regional natural reserves were trained to apply it in France, and mediators are currently being trained in western African biosphere reserves.

Finally, several criteria should be considered when choosing participants for the exercise. While the choice is flexible (it is possible to invite a new participant in the course of the exercise), the process gains from having access to an initial "core group" that will be present throughout the process of coconstruction. Apart from the compulsory reflection on the representativeness and legitimacy of the participants, which is commonly discussed in any participatory approach (Steyaert and Lisoir 2005), the composition of the core group can give priority to different factors. Linkages between stakeholders in resource management that occur at different spatial and institutional levels may enhance some cross-scale interactions that can empower local level user groups in creating social and political capital (Adger et al. 2005). Ensuring that less powerful stakeholders are involved as a means of promoting an equitable outcome of the participatory process may also be a determining criterion (Barnaud et al. 2008).
Four types of situations were encountered during the testing process:

1. Priority was given to a scientific representation of the system. The participants were mainly researchers of topics related to the issue, and perhaps who had grounded experience of the field or were from very similar situations.

2. Priority was given to a global understanding of the system. The participants were chosen from extension services whose local experience legitimized their position to speak on behalf of the stakeholders that they frequently come in contact with. It is important to ensure that all activities that relate to the defined issue are covered but that over-representing any one activity is avoided (for example, inviting three foresters because there are three forest companies working in the territory).

3. Priority was given to the involvement of local stakeholders who have an overall view of the system. The participants were selected from local stakeholder representatives who were chosen for their legitimacy (for example, they were elected democratically or were a leader of a professional organization) and for the relevance of their activity to the initial question.

4. Priority was given to the involvement of local stakeholders while seeking to cover the diversity of the system. Emphasis was placed on selecting local stakeholders whose actual practices were relevant to a particular question rather than selecting formal leaders of groups of stakeholders.

The position and status of researchers in the process was variable, and the significance of this is still being debated among the companion modeling community. The general rule is that researchers with knowledge of the context and major processes (social, technological, economic, ecological, and political) should be engaged. Some bring expertise to the initial stage, while others will be engaged at a specific workshop (for example, the discussion on system dynamics or the design of the interactions diagram) if the participants feel there is a need for expertise on a particular topic. This differentiation is relatively easy in the field of ecological sciences. 
It is problematic in the field of social sciences where the researcher may play the role of the "expert" who has a global view of the social relationships or economic flows but who will frequently be confronted with diverging points of view raised by the stakeholders who may have greater legitimacy to speak about social or economic issues (Charles et al. 2008).

Additional factors such as the choice of the venue and the duration and frequency of the meetings depend on many issues that are external to the exercise itself. But some principles should be negotiated and respected if the method is to be successfully applied. For example, it is desirable that the location of meetings is easily accessible to participants, and is on neutral ground. If not, this should be acknowledged lest it become an overt or hidden issue within the proceedings. Each meeting should be planned to last at least two hours, and the participants must remain focused on the collaborative exercise. In order to permit participants to keep a precise record of the decisions made and to follow up easily the step-by-step running of the ARDI method, the ideal is to conduct all the workshops over a period not exceeding one month. The meetings may be held in one of the following formats: (a) in a two-and-a-half-day workshop, (b) during one half-day per week, or (c) over three separate days. Ideally, the choice should be negotiated with the participants.

\section{THE ARDI METHOD}

ARDI is an acronym of the four French words, "Acteurs", "Ressources", "Dynamiques", and "Interactions", that identify the four steps the method uses to elicit stakeholder mental models of the system they are working or living in. Thus, it allows the progressive emergence of a shared representation of the components and dynamics of the system by describing stakeholders, the resources, the processes, and the interactions between them. The steps involved in conducting an ARDI process are described in detail below.

\section{Co-constructing a common representation}

The first step of the companion modeling approach following the ARDI method focuses on collectively identifying the principal stakeholders who are concerned with the key question, their management entities, the resources used, and the main processes that are driving changes that affect these resources. The group that takes part in the co-construction of the model must clearly address a key question, the formulation of which is adapted to the issue at stake. In the South African case study, the issue that was tackled was formulated as follows: What do you think about water resources use and management in the Crocodile Catchment? What is driving change in the flow of the Crocodile River? For the ARDI exercise, the issue was first split into the following three questions:

1. What are the main stakeholders that interact with the river and its flow?

2. What are the main resources of the catchment in relation to water flow?

3. What are the main processes that drive changes in the Crocodile Catchment that affect the river flow?

Depending on the extent and complexity of the territory concerned and on the level of detail required, the collective response to each of these three questions can take between 1 and 3 hours. It is important that the order of questions be respected and the facilitator take care that each participant has the opportunity to voice an opinion. In the sessions we facilitated, the following simple procedure was adopted: (1) a drawing was made on an interactive white board that was visible to and understandable by all the participants, (2) for each element of ARDI, each participant had the opportunity to respond, and (3) only one concept was be proposed at a time. This formal procedure is used to systematically elicit a representation of the system and to avoid premature digression and discussion.

To facilitate the sharing of mental models and representations, the answers to the questions are formulated as lists of words with a minimum of coding, which makes it possible to easily classify the information and represent it on a diagram. The workshop is generally led by two people: a facilitator and an observer/recorder.

A key role of the facilitator is to ensure clarity and general agreement about the terms or concepts used, such as when a response is either too generic (e.g., manager), or uses a term that can lead to confusion 
(e.g., ash can be a plant material, a woody plant, or the residue from a fire). The role of the observer/ recorder is to keep track of the exchange between members of the group or between one participant and the facilitator. Among the key interactions to monitor, three are particularly important:

1. By observing the attitudes of the participants to each other (who is supporting whose idea, who is arguing against whose idea), some social links can be revealed.

2. Writing down and analyzing the nature of arguments developed to support or to contradict a proposal permits the analyst to identify the domain of justification (Boltansky and Thévenot 1991) or the way participants frame the issues (Bouwen and Taillieu 2004) when they evaluate any submitted item.

3. Keeping track of the reasons advanced for changing a previously accepted concept or term is a good way to follow up the group dynamics.

The first aspect facilitates identification of social networks, the second facilitates better understanding of individual mental models, and the third facilitates keeping track of the path followed to reach an agreement.

For instance, in the Crocodile River process, after each ARDI exercise, the facilitator and the observer discussed their observations and identified, for each point that required discussion and argumentation, which justification domain (Boltansky and Thévenot 1991) the participants appealed to, in order to assert their choice. During the step used to identify the key processes that drive changes that affect the river flow in the Crocodile Catchment, 12 processes were mentioned by the 10 interviewees. Among these, biodiversity laws, climate change, forestry development, nutrient leaching, stream flow, water rights reallocation, and chemical modification were identified twice; drought, sediment load, tourism development, and crop market were identified three times; and population increase was identified seven times. The analysis of the ways these assertions were justified identified science, market/economics, and legal domains as being the most frequent (Fig. 1).

\section{Identifying key actors ("A")}

The first stage of the ARDI process culminates in the "actors" diagram, which is composed of the list of stakeholders and the corresponding management entities and the links between them (Fig. 2). The exercise proceeds in three stages. Initially, the participants simply list the stakeholders who they consider to be associated with the question. As long as new suggestions for stakeholders are proposed, the facilitator goes on with the next participant or begins a new round from the floor. Each actor proposed must be a direct stakeholder (people who use or whose practices have a direct impact on key resources of the territory), or an indirect stakeholder (people whose actions will encourage the direct stakeholders to change their practices). Generally, the indirect actors refer to people who either bear a public policy, enforce a regulation, or provide financial support. Even if they are likely to be outside of the territory, it is the way to account for decisions made at higher scales than the scales defined by the case study spatial limits. The facilitator adds each input to the interactive board by using a new label and colors to distinguish the category to which it belongs (for example, black case for the direct ones, blue for the indirect ones). The facilitator may suggest subclasses to increase the precision with which certain types of actors are defined (e.g., farmers may be subdivided into sugar cane and citrus farmers) or challenge the assignment to a category if there is not consensus in the room. A typical example of this type of intervention is the status given to the entity "herd". Certain participants will position it as a resource, others will regard it as an actor. When the grazing impact on grassland dynamics is a significant process, the facilitator may ask whether participants think that the herd is autonomous (it decides where, when, and how much it will graze), or if it depends mainly on the decisions of the shepherd/farmer. In the first case, the herd will be retained as a stakeholder; in the second case, it will be listed as a resource managed by the shepherd.

Next, the facilitator asks the participants to specify the links that exist between the identified stakeholders and to clarify this relationship in a simple way. Progressively, arrows are added according to suggestions made by the participants. The facilitator progressively shapes the diagram by bringing closer the stakeholders who have many relations and moving those away that do not have 
Fig. 1. Frequency of justification domains used by workshop participants to justify their selection of key processes that drive changes in the Crocodile Catchment.
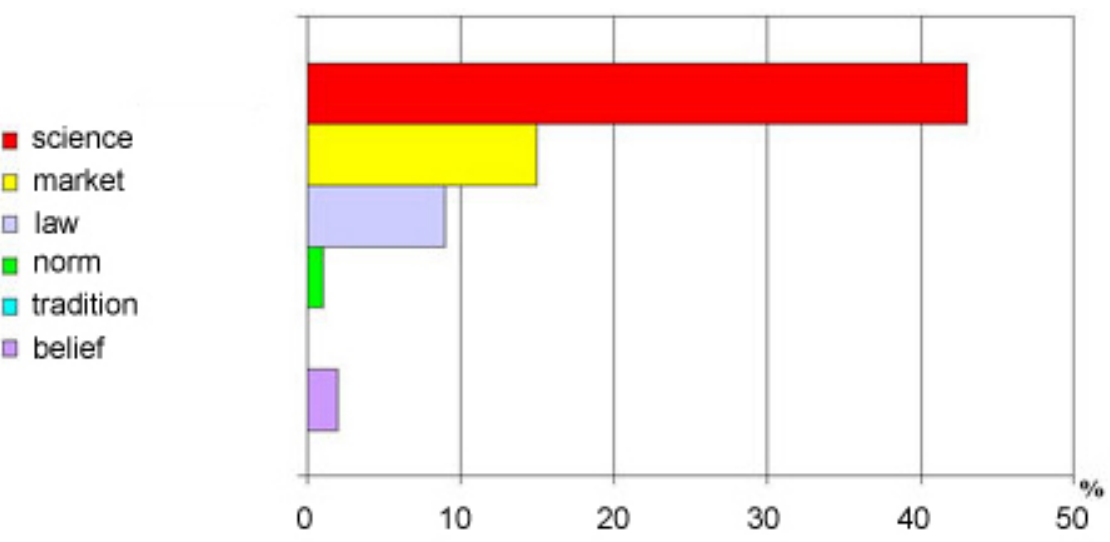

any. When the participants consider that the main interactions between actors have been represented, the facilitator can identify or question incongruities and gaps (e.g., no link between the municipalities and the developers) or point out stakeholders who have no relation with any others. In the latter case, the facilitator launches a deliberation on the relevance of retaining this actor in the diagram, while the observer keeps record of the decision made by the group and the justification for the decision (the landowner is a typical example of a stakeholder who does not have a link with anybody but who is often retained in the diagram because he/ she can easily block the development of the activities of another stakeholder).

Lastly, always adhering to the principle of the negotiation, the participants must identify and clarify the management entities used by each direct stakeholder. Those can be spatially explicit entities (forest plot, water catchment, dam), or not (fish, cash).

The diagram must clearly reflect the changes made during the subsequent steps in the ARDI process. Red letters are conventionally used for topics added; italics are used for terms proposed by the facilitator. Words that are crossed out represent topics that were eliminated when elaborating ongoing diagrams.
Figure 2 shows that when "Water Abstraction" was mentioned during the Interaction step of the ARDI process, "Rural Community" was acknowledged as not being an important stakeholder since the amount abstracted was considered to be insignificant. The rural community stakeholder concept was therefore eliminated. The irrigation farmer class was split into two categories in order to set apart commercial farmers, who were identified as consuming much less water than irrigation farmers. Foresters were also split into two categories according to the level of compliance with the Water Act. However, this decision was reconsidered at the end of the ARDI process. National and provincial authorities were aggregated because one was seen as being the arm of the other. Finally, two new stakeholders appeared during debates on interactions around the action "to pollute": developers and urban residents. In such a way, actors are added and removed from the representation in a discursive manner, the main point being that the category and its meaning are clarified as a social, dynamic process.

\section{Identifying key resources ('R')}

The second stage consists of listing the relevant resources of the territory according to the key stakeholders previously identified, the word 
Fig. 2. ARDI stage 1 at Crocodile River: "What are the main stakeholders that seem to be able to or need to play a decisive role in managing the river flow?" Words or concepts written in red were added during the later steps of the ARDI. Words or concepts written in italics were proposed by the facilitator to get out of a deadlock. A crossed box means that the idea was finally rejected.
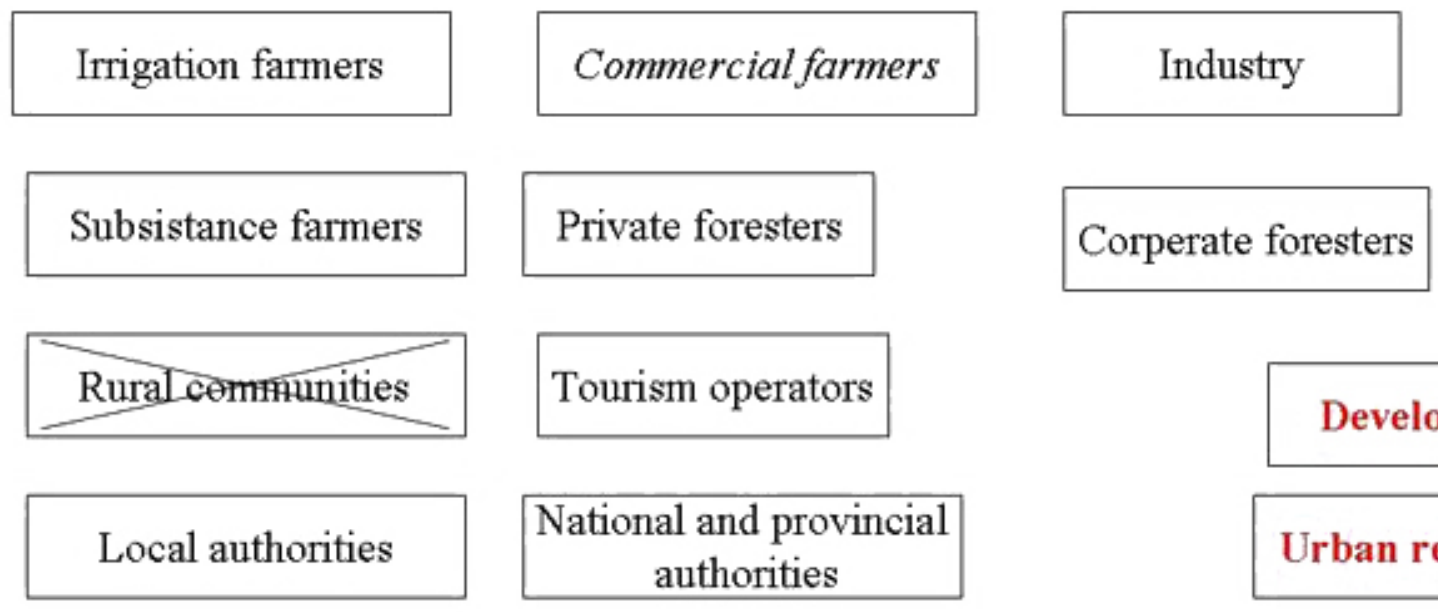

Developer

Urban resident

"resource" applying exclusively to goods or products used by any of the stakeholders (Fig. 3). During the collaborative construction of the list, the principal types of resources are often grouped within five main categories (infrastructure, water, minerals, plants, and animals). For each resource mentioned, the speaker is asked to justify his or her choice and is encouraged to specify which indicator seems to be the most relevant to making management decisions regarding that resource. This indicator can be quantitative or qualitative, and if there is debate or disagreement, several indicators may be applied to a particular resource. Participants are encouraged to explain which characteristics of the resource are being considered before making a decision about that resource. Because certain resources are temporary, one may have to specify the period of existence (season, favorable year) and/ or length of existence (lifespan of a building, time for filling of a dam). The resources functioning as exogenous variables but whose characteristics are critical in operating the system can also be mentioned (e.g., the rainfall in arid or dry zones). This set of indicators will be used afterwards, during the model implementation and the development scenarios steps, to visualize and compare the stakeholders' points of view (Etienne et al. 2003).
Several changes were made to the Resource diagram during the modeling process: when the process "Nutrient Leaching" was adopted at stage 3, the animals farmed near the river, such as trout, crocodiles, or ostriches, were added. But the stakeholders had problems finding a generic word. Finally, after a while, the facilitator's suggestion of "Farmed Animals" was accepted.

\section{Identifying key processes ('D for dynamics")}

The third stage of the ARDI process consists of listing the main processes that drive changes in the territory in relation to the question (Fig. 4). These processes can deal with ecological dynamics (e.g., vegetation transitions or water flow), economic dynamics (e.g., market forces, amount of subsidies), or social dynamics (e.g., social cohesion, knowledge transfer). If the list is large, the facilitator asks the participants to rank the 10 main processes by assigning " 10 " to the most important one and " 1 " to the least. Then the facilitator sums up the scores given by each participant and selects the five processes that get the highest score. For these processes, diagrams are drawn to reflect participant perspectives on what forces are driving changes with respect to which resources. 
Fig. 3. ARDI stage 2 at Crocodile River: "What are the main resources of the catchment and the key information needed to support their management?" Words or concepts written in red were added during the later steps of the ARDI. Numbers rank the items from the most (5) to the least important (1).
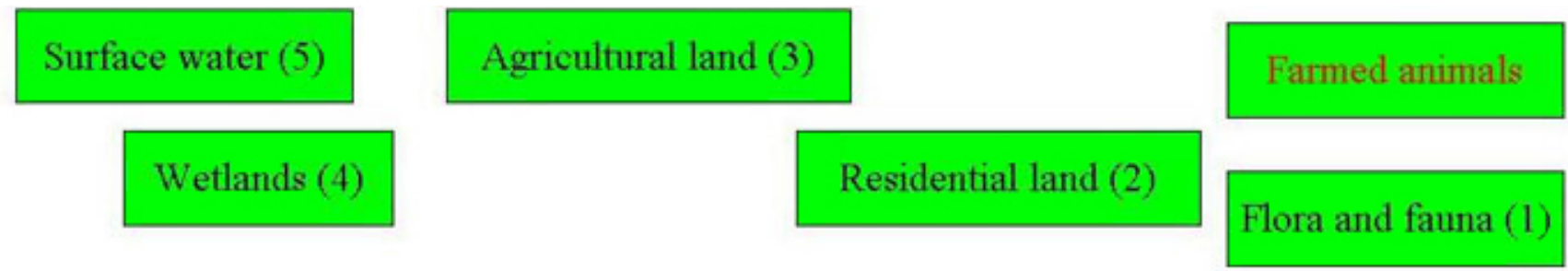

When dealing with ecological dynamics, participants may agree on the successive states taken by the vegetation and specify the factors that cause the transition from one state to another, including the time required to move from one state to the next. The diagram can be designed either in situ or as a response to a proposal designed by an expert. In the two options, the diagram must clearly distinguish between the dynamics related to human actions (effect of the techniques currently implemented) and natural dynamics (consequence of some types of uses being abandoned). A similar diagram can be applied to the dynamics of water.

At the end of this stage, it is advisable to review and revise the diagrams and to identify possible gaps. Three types of gaps may be identified:(1) an activity or a resource was identified but no participant possessed enough knowledge about it. The group then agrees to call upon an expert and nominates a person to identify and mobilize the expert; (2) an important actor was forgotten at the time of the preparatory phase, and the group was concerned by this absence. The group then agrees to invite the person to the next phase; and (3) an actor, a resource, or a dynamic process were the subject of a total disagreement between two or more participants. The group then agrees on the choice of an expert and the type of information required from that expert in order to solve this deadlock.

Some comments were received and changes were made to the Process diagram during the following steps. When eliciting the impact of afforestation on the river flow, the acronym SFRA was chosen because it corresponds to the terms of the law: "stream flow reduction activity". When discussing the importance of wetlands, two new processes arose and were added: "Flow Reduction" and "Water Purification". The group could also not agree on a process that linked surface water to flora and fauna. After much discussion, the facilitator's suggestion of "Life Support" was accepted.

\section{Eliciting interactions ("I")}

The last stage of the ARDI method consists of synthesizing answers to the three preceding questions by stressing the interaction between users and resources (Fig. 5). It is a pivotal process in the exercise since it leads to the conceptual model that represents all interactions related to the key question. It is advisable to devote more time to this phase since it generally takes one half-day for a simple diagram (3-4 direct actors, 3-4 resources), and one day for a more complex diagram (5-8 direct actors, 5-10 resources). The group must then answer the following central question: How does each stakeholder use the resources and modify the processes?

The facilitator will begin this stage by distributing and summarizing the diagrams developed during the ARDI process, making a particular effort of clarifying if new people were integrated into the group. When the diagrams are relatively simple, the facilitator directly invites the participants to collectively construct an interaction diagram. For that, the facilitator puts the main resource in the middle of the diagram and proposes to position the direct stakeholders related to this resource. Each 
Fig. 4. ARDI stage 3 at Crocodile River: "What are the main processes that drive changes in the Crocodile Catchment that affect the river flow?" Words or concepts written in red were added during the later steps of the ARDI. Words written in italics were proposed by the facilitator to get out of a deadlock.

$\begin{array}{lll}\text { DF Drought frequency } & \text { SFRA Stream flow reduction activity } & \text { LS Life support } \\ \text { CP Crop production } & \text { FR Flow regulation } & \\ \text { NL Nutrient leaching (N) } & \text { WP Water purification } \\ \text { WH Water heating } & \\ \text { CM Chemical modification } & \\ \text { UPI Urban population increase } & \end{array}$

participant, in turn, chooses to add an interaction between a stakeholder and a resource or between a stakeholder and another stakeholder. The participant can either add a link on the collective diagram or ask to add one of the stakeholders of the list, who has not yet been included on the collective diagram. Each new interaction suggested must include a verb that specifies the type of action that generates the link. The proposer must justify their choice and indicate, if they know, the type of information used by the actors to make the corresponding decision (e.g., I reduce my use of irrigation water because the water level in my dam is less than $3 \mathrm{~m}$; I will look for an agreement with the Water User Association because more than $30 \%$ of the inhabitants complain about the lack of drinking water). Finally, when all the arrows are drawn, the participants locate on the diagram the key processes identified during the " $D$ " stage of the ARDI process by writing down their acronym besides the arrow to represent an interaction that is believed to strongly affect the resource or stakeholder.

When the diagrams become too complex, it is preferable to proceed by dividing up the exercise into several manageable portions. Two options are possible. If several key goals were clearly identified to be at stake during the co-construction process, the facilitator proposes to create a diagram of interactions for each of these stakes and leads the procedure described in the preceding paragraph as many times as is necessary to complete the diagram.
In this case, the facilitator must take care that the resources and the stakeholders mentioned by the participants continue to relate well to the chosen stake, and in case of doubt, to clarify the considered link. If key goals are not clearly identified, the facilitator proposes to group the resources into categories, and then constitutes working groups on the three or four categories that appear to be most important to the participants. In this case, it is necessary to add a phase of combining and comparing the three or four built diagrams.

The role of the facilitator during the "Interaction" step is particularly important and delicate since he/ she is responsible for constructing an easily accessible and recognizable diagram at the same time as facilitating interactions and inputs (taking care to avoid confusing representations and "crossed arrows", etc). The facilitator needs to pay attention to the clarity of inputs from participants (while avoiding polarization and putting them in uncomfortable positions), and needs to regularly revisit inputs that are not integrated into the diagram (i.e., boxes without arrows) without forcing the participants too much. The facilitator simultaneously seeks to achieve three objectives: (1) to gradually prepare a common diagram that is comprehensible to all, (2) to identify clear and indisputable interactions, and (3) to leave the possibility for addressing lapses of memory. Additionally, the facilitator's role is to ask each participant to reformulate their input so as to avoid uninformative verbs (e.g., the forester manages the land, the farmer 
Fig. 5. ARDI stage 4 at Crocodile River: "How does each stakeholder use the resources and modify the processes?" White boxes indicate stakeholders, green boxes indicate resources, boldfaced letter codes indicate processes, and blue text indicates actions. Words or concepts written in red were added during the later steps of the ARDI.

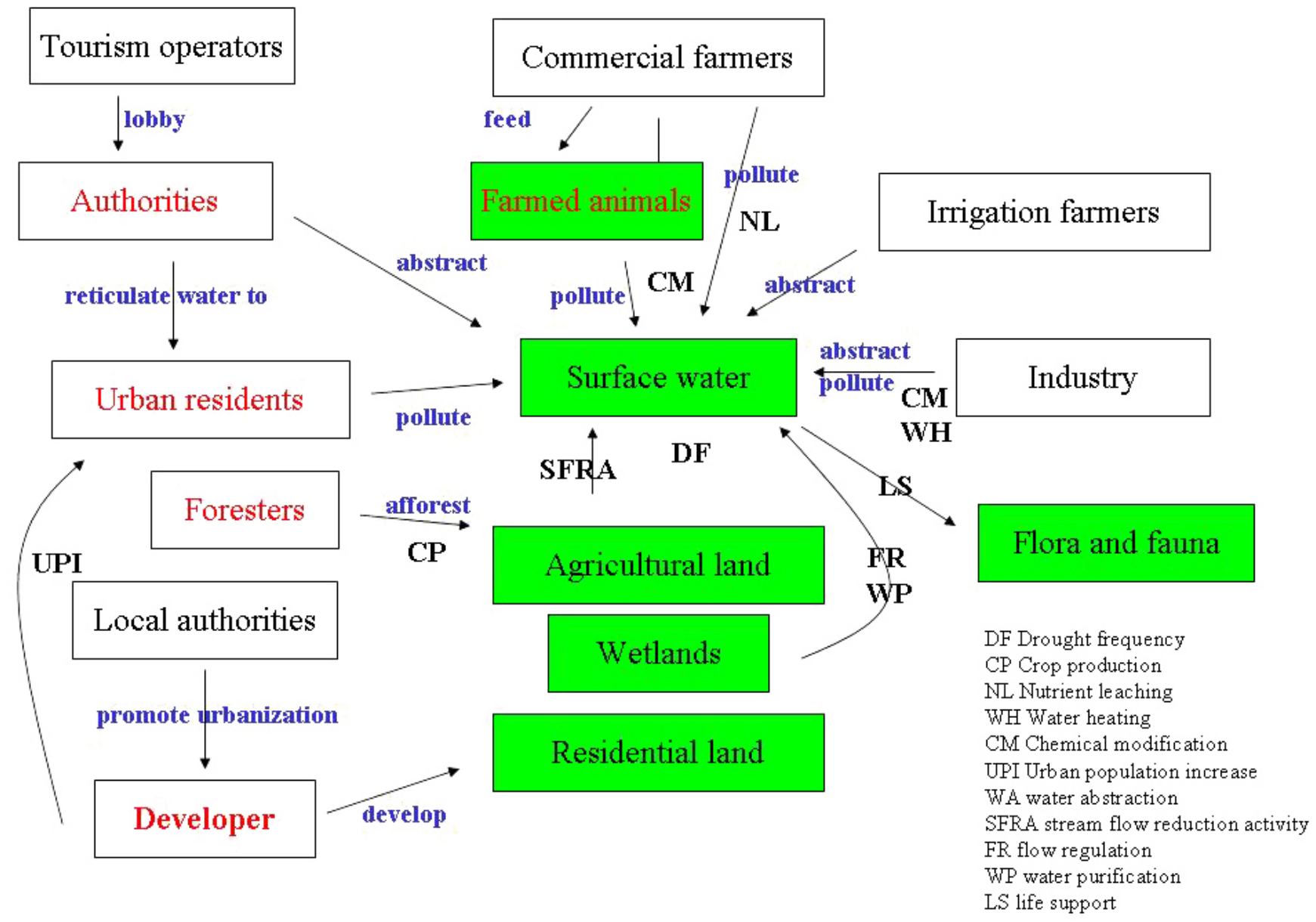

farms the field, the manager manages the budget) or to retain only the interactions that make sense according to the question (e.g., in an exercise on fire prevention and urbanization, the interaction between the cereal farmer and his crop field was restricted to ploughing the stubble after harvest because it was the only one that impacts land sensitivity to fire).

This interaction step is generally the richest and most interesting of the co-modeling process. To capture this, it is essential to keep a record of the process of constructing the four diagrams. There is specific value in knowing why and how a particular actor, resource, or interaction was mentioned, retained, eliminated, or transformed. It is possible to use many means to reach this goal: audio recording (very comprehensive but very time consuming to analyze), the use of a secretary who is dedicated to this task (very effective because they can quickly give an account of the sequence followed and how decisions were justified, but it requires an additional person), or the use of an interactive table or a digital camera to take a series 
of pictures of the diagrams as they are being constructed (very demonstrative but it requires either particular equipment or a person partially dedicated to the exercise).

\section{Taking the perspectives further}

The completion of these four stages leads to the establishment of a conceptual model. This model is a critical output of the ARDI process because it is a graphical representation of how the stakeholders perceive the system to function. This has fundamental implications for the next stages: designing and implementing a management plan for the territory based on the collaboratively established understanding captured in the diagrams. Two options arise for the working group that will take the ARDI steps to the next stage: (1) work out a proposal for a management plan (e.g., concerted research plan, charter of sustainable development) based on the conceptual diagram, or (2) develop a computer simulation model that will assist in decision making and dialogue. In the first case, the thinking will be focused on the territory and its priorities of development, education, and research. In the second case, the thinking will focus on the implementation of a computer model or a roleplaying game to help stakeholders transport themselves into the future and imagine and collectively envision adaptive co-management scenarios. In both cases, the ARDI method is valuable and useful because it works with a collectively established conceptualization of the territory and provides a concrete tool for applying the concepts of adaptive management.

The ARDI method can also be applied with the specific research goal of comparing individual and collective mental models, or monitoring changes in mental models during a collaborative process. In this case, the approach can be split into two steps: first, a set of individual interviews where each stakeholder's mental model of the system's form, function, state, and dynamics is elicited; then a collective exercise of co-construction of what could be called a shared representation of the system (Mathevet et al. 2011). This particular approach requires additional logistical arrangements and agreements with participants, and is useful as a tool for collaborative reflection on the emergence of comanagement of a particular resource.
In some aspects, the method has similarities with problem structuring methods, such as the use of a model as a transitional object, the emphasis put on the group process, and the importance of facilitation skills (Eden and Ackermann 2006). As it is concentrated on the preliminary issue conceptualization stage of modeling and on the visualization of a shared mental model, it can also be compared with or completed by other methods developed for systems thinking and applied to natural resources management, such as hexagon diagrams (Hodgson 1992), group model building (Richardson and Andersen 1995), influence diagrams (Cain et al. 1999), causal loop modeling (Sterman 2001), or stock and flow diagrams (Takahashi 2008).

The contribution of the ARDI method to decentralized democratic approaches to natural resources management should be critically assessed in the light of the work presented here (see D. Du Toit, H. Biggs, and S. Pollard unpublished manuscript). Three sensitive aspects, identified as critical issues in recent reviews of methods to enhance stakeholders' participation in environmental management (Lynam et al. 2007, Reed 2008, Voinov and Brown 2008), need to be highlighted. First, highly skilled facilitation is required to ensure mutual respect, conviviality, and psychological safety in order to get to a common empowerment of the participants. Specific skills are required to anticipate unexpected reactions due to the peculiarity of the process, to consider all types of knowledge as legitimate, and to be sensitive and responsive to the power relationships among the people involved in the collaborative workshops.

Second, special attention has to be paid to the legitimacy of the process and representativeness of the people involved. Thus, the method should be tailored to a particular decision-making context, and should take due consideration of the objectives, nature, and status of participants and appropriate level of engagement.

Third, the objectives of the participatory process must be clearly defined and agreed upon at the beginning of the process, and regularly recorded and revisited while proceeding. This goal is likely to be frequently challenged by the complexity and uncertainty presented by the emerging mental model. 
Specifically, the application of the ARDI method has demonstrated strengths in understanding stakeholders' perspectives and values, and providing an effective way to get to a shared representation of a complex system. It supports stakeholders' participation in a process that emphasizes empowerment, equity, trust, and learning (Reed 2008). It allows an integration of lay, technical, and scientific knowledge by stressing the choice of clear and simple terms, and providing access to different ways of thinking about and representing a situation. The method takes care that practitioners not be concerned when results are contradictory or unexpected, and helps initial individual surprises to be transformed into unexpected collective discoveries (Lynam et al. 2007).

Responses to this article can be read online at: http://www.ecologyandsociety.org/voll6/iss 1/art44/ responses/

\section{Acknowledgments:}

The authors wish to thank the French Institute for Biodiversity and the UNESCO-MAB program for the financial support provided to French and Western African case studies, and the South African National Parks and Water Research Commission for the South African case study. We also want to acknowledge the participants in the many workshops that were organized in France and in Western and South Africa to develop and validate this methodology.

\section{LITERATURE CITED}

Adger, W. N., K. Brown, and E. L. Tompkins. 2005. The political economy of cross-scale networks in resource co-management. Ecology and Society 10 (2):9. [online] URL: http://www.ecologyandsociety. org/vol10/iss $2 /$ art $9 /$.

Anselme, B., F. Bousquet, A. Lyet, M. Etienne, and B. Fady. 2010. Modelling of spatial dynamics and biodiversity conservation on Lure mountain (France). Environmental Modelling \& Software 25 (11):1385-1398.
Barnaud, C., G. Trébuil, P. Dumrongrojwatthana, and J. Marie. 2008. Area study prior to companion modelling to integrate multiple interests in upper watershed management of northern Thailand. Southeast Asian Studies 45(4):559-585.

Beratan, K. 2007. A cognition-based view of decision processes in complex social-ecological systems. Ecology and Society 12(1):27. [online] URL: http://www.ecologyandsociety.org/vol12/iss1/ $\underline{\operatorname{art} 27 /}$.

Biggs, H., D. Du Toit, M. Etienne, N. Jones, A. Leitch, T. Lynam, S. Pollard, and S. Stone-Jovicich. 2008. A preliminary exploration of two approaches for documenting mental models held by stakeholders in the Crocodile catchment, South Africa. WRC Report KV 216/08, Water Resource Commission, Gezina.

Boltansky, L., and L. Thévenot. 1991. De la justification. Gallimard, Paris, France.

Bosch, O. J., C. A. King, J. L. Herbohn, I. W. Russell, and C. S. Smith. 2007. Getting the big picture in natural resource management: systems thinking as 'method' for scientists, policy makers and other stakeholders. Systems Research and Behavioral Science 24(2):217-232. [online] URL: http://onlinelibrary.wiley.com/doi/10.1002/sres.818/ pdf.

Bousquet, F., O. Barreteau, P. d'Aquino, M. Etienne, S. Boissau, S. Aubert, C. Le Page, D. Babin, and J. C. Castella. 2002. Multi-agent systems and role games: an approach for ecosystem comanagement. Pages 248-285 in M. Janssen, editor. Complexity and ecosystem management: the theory and practice of multi-agent approaches. Elgar Publishers, Northampton.

Bouwen, R., and T. Taillieu. 2004. Multi-party collaboration as social learning for interdependence: developing relational knowing for sustainable natural resource management. Journal of Community and Applied Social Psychology 14:137153.

Cain, J., C. Batchelor, and D. Waughray. 1999. Belief networks: a framework for the participatory development of natural resource management strategies. Environment, Development and Sustainability 1:123-133. 
Charles, M., F. Chlous-Ducharme, E. Faugère, and M. Wintz. 2008. Science et démocratie dans la gestion de la nature : des ethno-sociologues pris dans la modélisation d'accompagnement. VertigO 8 (2). [online] URL: http://vertigo.revues.org/4999.

Collectif ComMod. 2006. Modélisation d'accompagnement. Pages 217-228 in F. Amblard and D. Phan, editors. Modélisation et simulation multi-agents : applications aux sciences de l'homme et de la société. Hermès Sciences, Londres.

Costanza, R., and M. Ruth. 1998. Using dynamic modelling to scope environmental problems and build consensus. Environmental Management 22:183-195.

Daré, W., R. Ducrot, A. Botta, and M. Etienne. 2009. Repères méthodologiques pour la mise en oeuvre d'une démarche de modélisation d'accompagnement. Cardère éditions, Avignon, France.

Daré, W., A. Van Paassen, R. Ducrot, R. Mathevet, J. Queste, G. Trébuil, C. Barnaud, E. Lagabrielle. 2010. Apprentissage des interdépendances et des dynamiques. Pages 223-250 in M. Etienne, editor. La modélisation d'accompagnement: une démarche participative en appui au développement durable. Quae éditions, Versailles, France.

Eden, C., and F. Ackermann. 2006. Where next for problem structuring methods. Journal of the Operational Research Society 57(7):766-768.

Etienne, M. 2006. Companion modelling: a tool for dialogue and concertation in Biosphere Reserves. UNESCO-MAB Technical Notes 1:44-52.

Etienne, M., editor. 2010. La modélisation d'accompagnement: une démarche participative en appui au développement durable. Quae éditions, Versailles, France.

Etienne, M., C. Le Page, and M. Cohen. 2003. A step-by-step approach to building land management scenarios based on multiple viewpoints on multiagent system simulations. Journal of Artificial Societies \& Social Simulations 6(2). [online] URL: http://jasss.soc.surrey.ac.uk/6/2/2.html.

Gurung, T. R., F. Bousquet, and G. Trébuil. 2006. Companion modeling, conflict resolution, and institution building: sharing irrigation water in the
Lingmuteychu Watershed, Bhutan. Ecology and Society 11(2):36. [online] URL: http://www.ecolog yandsociety.org/vol11/iss2/art36/.

Hodgson, A. 1992. Hexagons for systems thinking. European Journal of Operational Research 59 (1):220-230.

Holling, C. 1978. Adaptive environmental assessment and management. John Wiley, London, UK.

Jones, N. A., H. Ross, T. Lynam, P. Perez, and A. Leitch. 2011. Mental models: an interdisciplinary synthesis of theory and methods. Ecology and Society 16(1):46. [online] URL: http://www.ecolog yandsociety.org/vol16/iss1/art46/.

Lynam, T., W. de Jong, D. Sheil, T. Kusumanto, and K. Evans. 2007. A review of tools for incorporating community knowledge, preferences and values into decision making in natural resources management. Ecology and Society 12(1):5. [online] URL: http://www.ecologyandsociety.org/vol12/iss 1/ $\underline{\operatorname{art5}}$.

Mathevet, R., M. Etienne, T. Lynam, and C. Calvet. 2011. Water management in the Camargue Biosphere Reserve: insights from comparative mental models analysis. Ecology and Society 16 (1):43. [online] URL: http://www.ecologyandsociety. org/vol16/iss 1/art43/.

Ozesmi, U., and S. L. Ozesmi. 2004. Ecological models based on people's knowledge: a multi-step fuzzy cognition mapping approach. Ecological Modeling 176:43-64.

Reed, M. S. 2008. Stakeholder participation for environmental management: a literature review. Biological Conservation 141(10):2417-2431.

Richardson, G., and D. Andersen. 1995. Teamwork in group model building. Systems Dynamics Review 11(2):113-137.

Röling, N. 2002. Beyond the aggregation of individual preferences; moving from multiple to distributed cognition in resources dilemmas. Pages 25-66 in C. Leeuwis and R. Pyburn, editors. Wheelbarrows full offrogs: social learning in rural resource management. Royal van Gorcum Assen, The Netherlands. 
Rouan, M., C. Kerbiriou, H. Levrel, and M. Etienne. 2010. Sheep, turf and bikes: a co-modelling process of social and natural dynamics on the isle of Ouessant. Environmental Modelling \& Software 25 (11):1399-1412.

Rouse, W. B., and N. M. Morris. 1986. On looking into the black box: prospects and limits in the search for mental models. Psychological Bulletin 100 (3):349-363.

Simon, C., and M. Etienne. 2010. A companion modelling approach applied to forest management planning. Environmental Modelling \& Software 25 (11):1371-1384.

Souchère, V., L. Millair, J. Echeverria, F. Bousquet, C. Le Page, and M. Etienne. 2010. Co-constructing with stakeholders a role-playing game to initiate collective management of erosive runoff risks at the watershed scale. Environmental Modelling \& Software 25(11):1359-1370.

Sterman, J. 2001. Systems dynamics modelling: tools for learning in a complex world. California Management Review 43(1):8-25.

Steyaert, S., and H. Lisoir. 2005. Participatory methods toolkit. A practitioner's manual. King Baudouin Foundation and the Flemish Institute for Science and Technology Assessment, Brussels, Belgium.

Takahashi, Y. 2008. Dynamic simulation modelling using descriptive information in natural language. International Journal of Simulation and Process Modelling 4:215-222.

Van den Belt, M. 2004. Mediated modelling: a system dynamics approach to environmental consensus building. Island Press, Washington, D.C.

Voinov, A., and F. Bousquet. 2010. Modelling with stakeholders. Environmental Modelling \& Software 25(11):1268-1281.

Voinov, A., and E. J. Brown. 2008. Lessons for successful participatory watershed modeling: a perspective from modeling practitioners. Ecological Modelling 216:197-207.

Walters, C. 1986. Adaptive management of renewable resources. McGraw Hill, New York. 